\title{
CaXyn30B from the solventogenic bacterium Clostridium acetobutylicum is a glucuronic acid-dependent endoxylanase
}

\author{
Casey Crooks ${ }^{1 *} \mathbb{D}$, Liangkun Long ${ }^{1,2}$ (1) and Franz J. St John ${ }^{1}$ (D)
}

\begin{abstract}
Objective: We previously described the structure and activity of a glycoside hydrolase family 30 subfamily 8 (GH30-8) endoxylanase, CaXyn30A, from Clostridium acetobutylicum which exhibited novel glucuronic acid (GA)-independent activity. Immediately downstream from CaXyn30A is encoded another GH30-8 enzyme, CaXyn30B. While CaXyn30A deviated substantially in the highly conserved $\beta 7-\alpha 7$ and $\beta 8$-a8 loop regions of the catalytic cleft which are responsible for GA-dependence, CaXyn30B maintains these conserved subfamily 8 amino acid residues thus predicting canonical GA-dependent activity. In this report, we show that CaXyn30B functions as a canonical GA-dependent GH30-8 endoxylanase in contrast to its GA-independent neighbor, CaXyn30A.

Results: A clone expressing the catalytic domain of CaXyn30B (CaXyn30B-CD) exhibited GA-dependent endoxylanase activity. Digestion of glucuronoxylan generated a ladder of aldouronate limit products as anticipated for canonical GA-dependent GH30-8 enzymes. Unlike the previously described CaXyn30A-CD, CaXyn30B-CD showed no activity on arabinoxylan or the generation of appreciable neutral oligosaccharides from glucuronoxylan substrates. These results are consistent with amino acid sequence comparisons of the catalytic cleft and phylogenetic analysis.
\end{abstract}

Keywords: Glycoside hydrolase, Xylanase, GH30, Glucuronoxylan, Bioconversion, Biorefinery

\section{Introduction}

Xylan represents the most abundant form of hemicellulose and consists of $\beta$ - $(1,4)$-linked D-xylose units. Effective use of xylan in applications including production of renewable fuels, green chemicals and nutraceuticals would be greatly facilitated by the availability of xylanases with well-defined functions that enable the generation of specific product streams [1, 2]. Depending on the xylan source, the main xylan chain may be decorated with acetyl, $\alpha$-L-arabinofuranose or 4-O-methyl$\alpha$-D-glucuronic acid substitutions. The hydrolysis of

\footnotetext{
*Correspondence: casey.crooks@usda.gov

${ }^{1}$ Institute for Microbial and Biochemical Technology, Forest Products Laboratory, USDA Forest Service, One Gifford Pinchot Drive, Madison, WI 53726, USA

Full list of author information is available at the end of the article
}

xylan by endoxylanases is significantly influenced by the xylan substitution characteristics. For strict endoxylanases, more xylan chain substitutions typically result in lower observed activity. GH30-8 endoxylanases are dual domain enzymes consisting of a $(\beta / \alpha)_{8}$-barrel containing the catalytic determinants with an obligatory stabilizing side $\beta$-sandwich structure tightly associated with the $(\beta / \alpha)_{8}$-barrel catalytic core through hydrophobic contacts [3-5]. Canonical GH30-8 enzymes exhibit a distinct specificity by requiring the recognition of GA substitutions at the catalytic-2b subsite for hydrolysis $[5,6]$. In part, this specificity is provided through a salt bridge interaction between the C6 carboxylate of GA and the guanidinium side-chain of a highly conserved arginine in the catalytic substrate binding cleft [6-8]. This arginine and surrounding motif (RR-motif) in the $\beta 8-\alpha 8$ loop region of these enzymes appears critical in determining

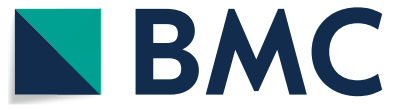

(c) The Author(s) 2020. This article is licensed under a Creative Commons Attribution 4.0 International License, which permits use, sharing, adaptation, distribution and reproduction in any medium or format, as long as you give appropriate credit to the original author(s) and the source, provide a link to the Creative Commons licence, and indicate if changes were made. The images or other third party material in this article are included in the article's Creative Commons licence, unless indicated otherwise in a credit line to the material. If material is not included in the article's Creative Commons licence and your intended use is not permitted by statutory regulation or exceeds the permitted use, you will need to obtain permission directly from the copyright holder. To view a copy of this licence, visit http://creativeco mmons.org/licenses/by/4.0/. The Creative Commons Public Domain Dedication waiver (http://creativecommons.org/publicdomain/ zero/1.0/) applies to the data made available in this article, unless otherwise stated in a credit line to the data. 
the substrate specificity of canonical GA-dependent GH30-8 enzymes (Fig. 1). We recently described a novel GH30-8 from Clostridium acetobutylicum, CaXyn30A (UniProt ID: Q97TI2), that lacks the highly conserved RR-motif and found it exhibited a novel GA-independent activity [9]. Encoded immediately downstream as part of a predicted three gene operon from the non-canonical, GA-independent, CaXyn30A is CaXyn30B (UniProt ID: Q97TI3) (Fig. 1). Phylogenetic and structural predictions and the conserved RR-motif of CaXyn30B suggest that this enzyme will exhibit canonical GH30-8 GA-dependent endoxylanase activity exemplified by the previously described GH30-8 endoxylanase from Bacillus subtilis, BsXynC, or the gram negative representative, EcXynA, from Erwinia chrysanthemi $[5,6]$. Here we describe the biophysical functional parameters of this genetically linked GH30-8 enzyme and confirm that it functions primarily as a canonical GH30-8 GA-dependent endoxylanase.

\section{Main text \\ Methods \\ Chemicals}

All general use chemicals were at least ACS grade. Molecular biology reagents were purchased from New England Biolabs (Ipswich, MA). For xylanase assays beechwood xylan (BX) was obtained from Sigma (St. Louis, MO), wheat arabinoxylan (WAX) and xylohexaose were obtained from Megazyme International (Wicklow, Ireland). Sweetgum wood xylan (SGX) was obtained from the laboratory of Dr. James F. Preston from the University of Florida. The aldotetrauronic acid (GX3) was prepared

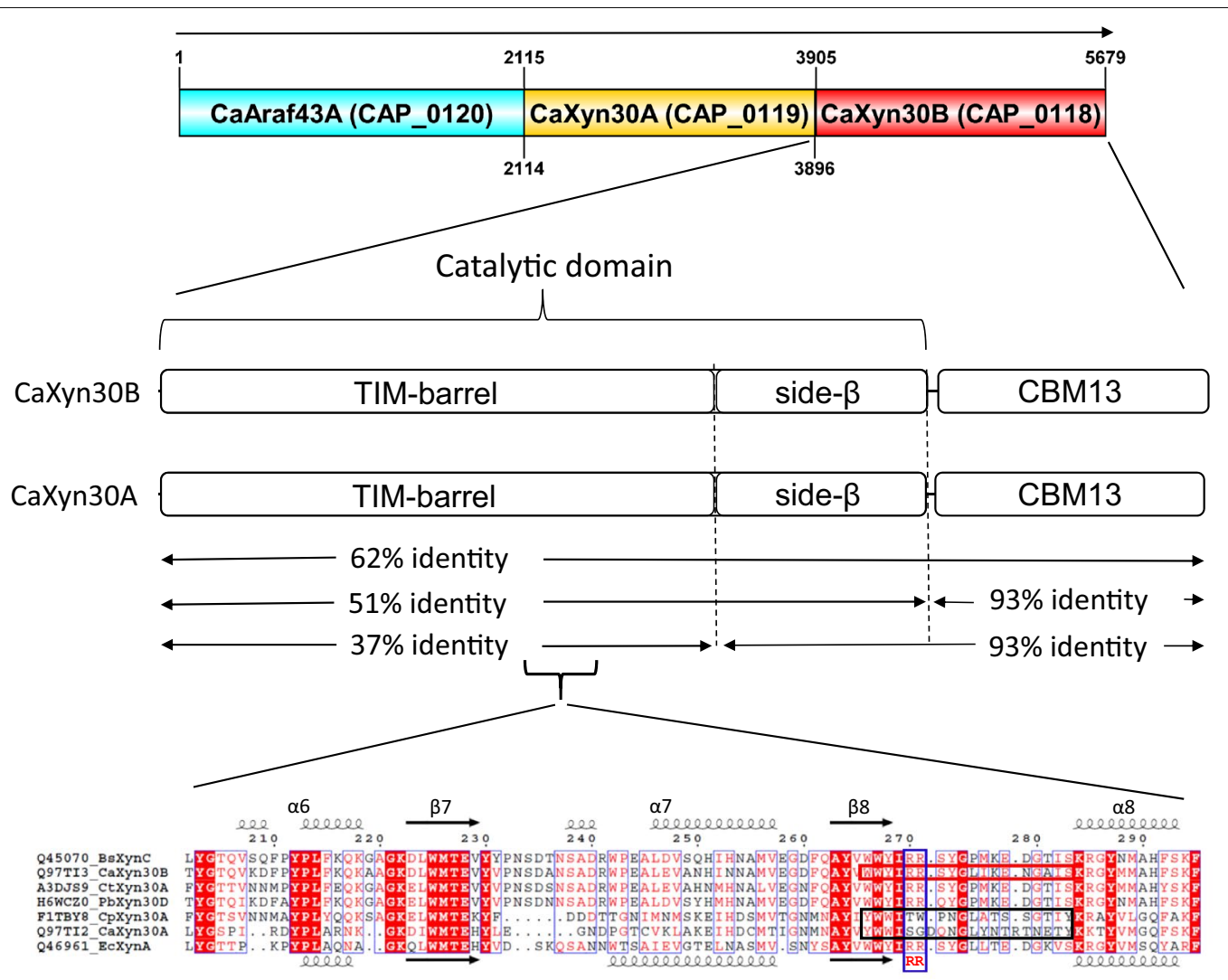

Fig. 1 Homology comparison of CaXyn30B (UniProt Q97T13) with CaXyn30A (UniProt Q97TI2) from C. acetobutylicum ATCC 824. Gene organization of the predicted operon containing CaXyn30B and the previously described GA-independent endoxylanase, CaXyn30A. GenBank locus tag identifiers are shown in parenthesis, the arrow indicates direction of transcription (top). Depiction of C-terminal bias of homology between these linked genes. While the proteins show high homology overall, the homology is heavily weighted towards the non-specificity determining C-terminal regions (middle). Alignment detail comparisons of the $\beta 7-a 7 / \beta 8$ - $a 8$ catalytic cleft of representative gram-positive GA-dependent GH30-8 endoxylanases from Bacillus subtilis (BsXynC), CaXyn30B (this study), Clostridium thermocellum (CtXyn30A), and Paenibacillus barcinonensis BP-23 (PbXyn30D), with the characterized GA-independent GH30-8 endoxylanases from Clostridium papyrosolvens (CpXyn30A), the linked CaXyn30A, and a gram-negative GA-dependent representative from Erwinia chrysanthemi (EcXynA) (bottom). The $\beta 8$-a8 loop region of CaXyn30B is boxed in red, the corresponding loop region in the GA-independent endoxylanases are boxed in black and the location of the GA coordinating "RR-motif" is boxed in blue and highlighted below. Operon prediction provided by www.microbesonline.org/operons/gnc272562.html 
by digesting $\mathrm{BX}$ to completion with the GH10 endoxylanase, $P b X y n 10 A 1 C D[10,11]$, and purifying using preparative TLC. Using the same TLC solvent system and detection described below for analytical studies, preparative TLC was performed using $20 \mathrm{~cm} \times 20 \mathrm{~cm}, 500 \mu \mathrm{m}$ thick silica gel $\mathrm{H}$ (no binder) plates. The PbXyn10A1CD BX hydrolysate was spotted in bands using the BandIT preparative TLC sample applicator from Miles Scientific (Newark, DE). The plate was developed with two ascensions and the sides were removed and developed to guide sample recovery. GX3 migration was identified using GXn standards and was isolated by washing the recovered silica in excess water. This volume was lyophilized, redissolved in water and the volume used in assays was determined empirically by comparison to quantified xylooligosaccharides.

\section{Cloning of CaXyn30B}

CaXyn30B (UniProt ID: Q97TI3), encoded on the pSOL1 megaplasmid, was isolated from genomic DNA obtained from Clostridium acetobutylicum ATCC 824. PCR amplification of the catalytic domain of CaXyn30B was performed using primers $5^{\prime}$-ctctaCCATGGcttcaaatgttatggttaatttagcctc- $3^{\prime}$ and $5^{\prime}$-cctcaCTCGAGgttgttagtaggctcaaatacc- $3^{\prime}$ and cloned into pET28b (Novagen) between the NcoI and XhoI sites using the sites as indicated with uppercase in the primers shown. The resulting construct was sequence verified and encodes a 402 amino acid C-terminal hexahistidine tagged expression product, CaXyn30B-CD.

\section{Protein expression of CaXyn30B-CD}

CaXyn30B-CD was expressed in E. coli using a modified auto-induction method derived from Studier et al. [12]. Briefly, the pET28-CaXyn30B-CD plasmid was transformed into Rosetta 2(DE3) cells and maintained under selection with $50 \mu \mathrm{g} / \mathrm{ml}$ kanamycin and $34 \mu \mathrm{g} / \mathrm{ml}$ chloramphenicol. A single colony was propagated in noninduction media $\left(50 \mathrm{mM} \mathrm{Na}{ }_{2} \mathrm{HPO}_{4}, 50 \mathrm{mM} \mathrm{KH_{2 }} \mathrm{PO}_{4}\right.$, $50 \mathrm{mM} \mathrm{NH}_{4} \mathrm{Cl}, 5 \mathrm{mM} \mathrm{Na}_{2} \mathrm{SO}_{4}, 2 \mathrm{mM} \mathrm{MgSO}, 0.5 \times$ trace metals mix (Technova), $0.5 \%$ glucose, $0.25 \%$ sodium aspartate) grown overnight at $37{ }^{\circ} \mathrm{C}$ and $250 \mathrm{RPM}$. A 1:150 inoculum was introduced into auto-induction media ( $0.5 \times$ terrific broth, $50 \mathrm{mM} \mathrm{NH}_{4} \mathrm{Cl}, 5 \mathrm{mM} \mathrm{Na}_{2} \mathrm{SO}_{4}$, $2 \mathrm{mM} \mathrm{MgSO}_{4}, 0.5 \times$ trace metals mix, $0.25 \%$ sodium aspartate) and grown for $40 \mathrm{~h}$ at $18{ }^{\circ} \mathrm{C}, 250$ RPM. Expression cultures were harvested, processed, and protein purified as previously described using $\mathrm{Ni}^{2+}$ immobilized metal affinity chromatography [11]. The eluted protein was desalted with two passages through Zeba $7 \mathrm{kDa}$ size exclusion spin column (Thermo Fisher Scientific). Protein size was confirmed and purity was empirically estimated at $>95 \%$ by SDS-PAGE [13] (not shown).

\section{Enzyme assays}

Enzyme activity optimization and specific activity was determined using the Nelson's test $[14,15]$ as previously described [8]. In $\mathrm{CaXyn30B}$ reactions, BX was used at $10 \mathrm{mg} / \mathrm{ml}$ and buffers at $30 \mathrm{mM}$. Reactions were initiated by addition of $200 \mathrm{ng}$ of CaXyn30B. For pH optimization the reaction temperature was $40^{\circ} \mathrm{C}$. Buffers included sodium acetate for lower $\mathrm{pH}$ range, a sodium acetate/ MES mixture for a middle $\mathrm{pH}$ range and sodium phosphate for a higher $\mathrm{pH}$ range. Following optimum reaction $\mathrm{pH}$ determination, optimum reaction temperature was determined using sodium acetate/MES buffer at $\mathrm{pH}$ 5.75. Specific activity was determined as described above, except that pH 6.0 acetate buffer was used instead of the acetate/MES two component buffer and the reaction was performed at $50{ }^{\circ} \mathrm{C}$ for $10 \mathrm{~min}$. One unit is defined as the amount of enzyme which liberates $1 \mu \mathrm{mol}$ of reducing terminal per minute.

\section{TLC and MALDI-TOF}

Hydrolysis reaction products were analyzed by thin layer chromatography (TLC) and Matrix-Assisted Laser Desorption/Ionization Time of Flight Mass Spectrometry (MALDI-TOF MS). TLC and MALDI-TOF MS were performed as previously reported $[8,16]$. Briefly, TLC reactions containing $10 \mathrm{mg} / \mathrm{ml} \mathrm{SGX,} 7.5 \mathrm{mg} / \mathrm{ml}$ WAX, or $5 \mathrm{mM}$ of the oligomeric substrates (GX3, X4, $\mathrm{X} 5, \mathrm{X} 6)$ were digesting in $50 \mu \mathrm{l}$ volumes $(25 \mu \mathrm{l}$ for GX3) with $20 \mu \mathrm{g} / \mathrm{ml}$ of $C a X y n 30 B, 28 \mu \mathrm{g} / \mathrm{ml} B c X y n C$ or $5 \mu \mathrm{g} /$ $\mathrm{ml} C a X y n 30 \mathrm{~A}$. CaXyn30B and BsXynC were incubated at $40{ }^{\circ} \mathrm{C}$ in $30 \mathrm{mM}$ sodium acetate $\mathrm{pH} 6$ buffer while $\mathrm{CaX}$ yn30A was incubated using $30 \mathrm{mM}$ sodium acetate $\mathrm{pH}$ 4. All TLC reactions were digested for $30 \mathrm{~min}$ and then heat inactivated at $95^{\circ} \mathrm{C}$ for $10 \mathrm{~min}$ and used directly for spotting on Analtech silica G plates spotting $5 \mu \mathrm{l}$ of the reaction in $1 \mu \mathrm{l}$ increments under warm air flow to allow drying between applications. Samples for MALDI-TOF were digested overnight using $3 \mu \mathrm{g} / \mathrm{ml}$ in $30 \mathrm{mM}$ pH 6.0 sodium acetate buffer. Samples were heat killed as above and were decationized using Dowex 50WX4 hydrogen form. The sample was added to the MALDI-TOF matrix 2,5-dihydroxybenzoic acid, spotted on the MALDI-TOF plate and dried for analysis. Mass analysis was performed using a Shimadzu MegaTOF at the University of Wisconsin, Biochemistry Instrumentation Facility.

\section{Results}

In a recent publication we characterized a confidently classified GH30 subfamily 8 endoxylanase (CaXyn30A, 
Q97TI2) from C. acetobutylicum which showed strikingly divergent function by exhibiting GA-independent endoxylanase activity as evidenced by the processing of WAX, release of neutral oligosaccharides from xylan polymers, and activity on neutral xylooligosaccharides [9]. This was attributed to amino acid sequence changes in the $\beta 8-\alpha 8$ and $\beta 7-\alpha 7$ loop regions of the enzyme. Other previous studies made a distinction between two primary GH30-8 branches [5]. This occurs between those which derive from Gram-positive bacteria versus those from Gram-negative bacteria. Most interestingly, while CaXyn30A derives from a Gram-positive bacterial host, it is nevertheless of the Gram-negative GH30-8 subtype. The adjacent enzyme, CaXyn30B (Q97TI3) which is the focus of this report, does not have any significant divergent gram-negative type sequence [5], is of the Gram-positive subtype and is expected to be a canonical functioning glucuronoxylanase. Interestingly, primary sequence analysis comparisons of $\mathrm{CaXyn} 30 \mathrm{~B}$ with $\mathrm{CaX}$ yn30A show that overall sequence homology is very high at about $62 \%$ identity for the mature protein (Fig. 1). This is unexpected considering their separate grouping into the Gram-type distinguished GH30-8s [5], which typically have identities less than $40 \%$. More detailed analysis reveals that the $\mathrm{C}$-terminal carbohydrate binding module (CBM, CBM13) which both enzymes share is a primary source of the high identities (i.e. 93\% identify for this separate domain), such that exclusion of the CBM13 module results in a $51 \%$ identity for the remaining protein. This high homology also extends into the catalytic domain stabilizing side beta-structure. Comparisons of the sequence representing only the specificity determining $(\beta / \alpha)_{8}$
TIM-barrel domain of the GH30 enzyme $[4,5,17]$ yields a lower level of sequence identity of $37 \%$, as expected for enzymes of different Gram-type grouping.

CaXyn30B-CD demonstrated GA-dependent activity on xylan substrates. MADLI-TOF MS analysis of glucuronoxylan digested by $\mathrm{CaXyn} 30 \mathrm{~B}$ liberated aldouronates as predicted for GA-dependent GH30-8 enzymes and lacked the accumulation of appreciable amounts of neutral xylooligosaccharides (Fig. 2). TLC analysis of digestion of model xylans showed CaXyn30B to be active on glucuronoxylan (SGX) but not arabinoxylan (WAX), similar to that observed for the defined GA-dependent endoxylanase, BsXynC, but unlike that observed for the previously described GA-independent enzyme, CaXyn30A, which also showed activity on arabinoxylan (Fig. 3). Digestion of GX3 yielded GX2 plus xylose, while digestion of xylotetraose showed no detectable activity, confirming the coordination of glucuronic acid in the catalytic-2b subsite (Fig. 3) [5, 8]. More activity than expected was observed in the hydrolysis of xylohexaose by $\mathrm{CaXyn30B} \mathrm{(Fig.} \mathrm{2).} \mathrm{Previous} \mathrm{reports} \mathrm{of} \mathrm{the} \mathrm{hydrolysis}$ rate difference between polymeric glucuronoxylan and neural xylooligosaccharides (typically exemplified by X6) were estimated at three orders lower for the unsubstituted linear xylooligosaccharide $[6,18,19]$. From our studies we estimate that $\mathrm{CaXyn30B}$ while still being predominantly GA-dependent, has a greater ability to hydrolyze neutral xylooligosaccharides then previously described GH30-8 GA-dependent endoxylanases. From Nelson's tests studies using X6 as substrate we estimate that CaXyn30B hydrolyzes X6 only 2-orders lower than a glucuronoxylan. Nevertheless, these results all confirm

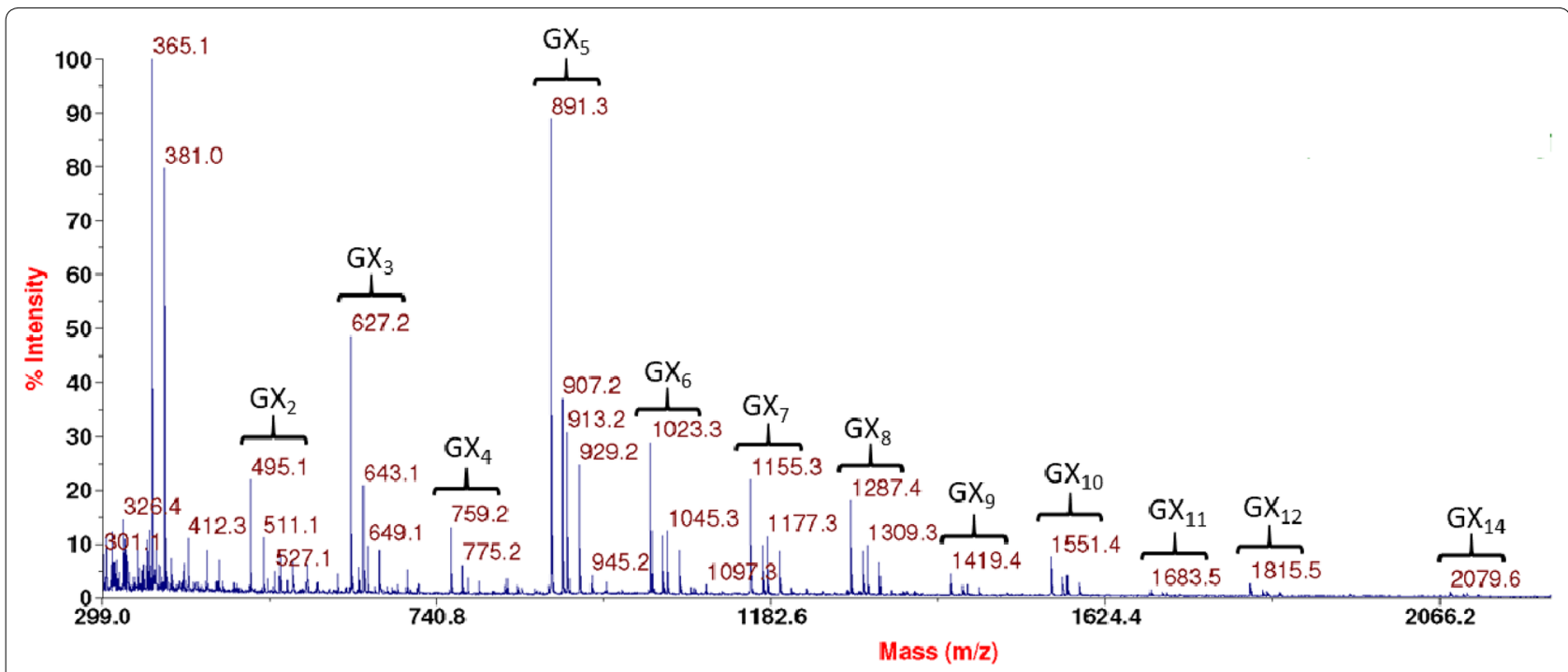

Fig. 2 MALDI-TOF results identify the anticipated series of aldouronates each which differs by a single anhydroxylose (132 Da) in mass. The primary peak for each cluster is the single sodium adduct, [GXn-Na]+ 


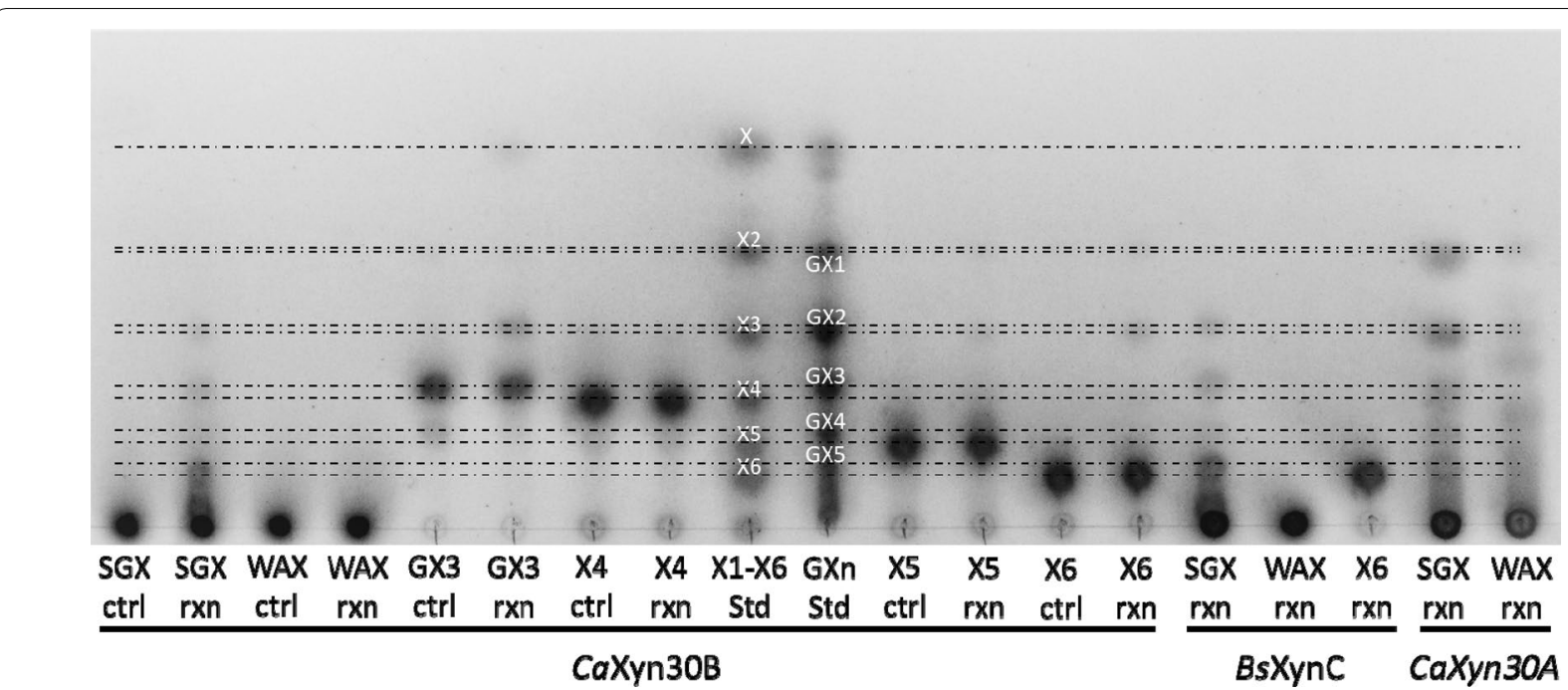

Fig. 3 TLC of model xylan and xylooligosaccharides digestions by CaXyn30B, the GA-dependent endoxylanase, BsXynC, and the previously described GA-independent endoxylanase, CaXyn30A. From left to right glucuronoxylan (sweetgum, SGX), arabinoxylan (wheat, WAX), aldotetrauronic acid (GX3), aldotriuronic acid (GX2), xylotetraose (X4), xylose to xylohexaose standards (X1-X6), aldouronate standards (GXn), xylopentaose (X5) and xylohexaose (X6)

the anticipated function CaXyn30B as a GA-dependent GH30-8 endoxylanase. The pH optimum of CaXyn30B$\mathrm{CD}$ was determined under three buffer systems spanning $\mathrm{pH} 3.5-8.0$ and found to be $\mathrm{pH} 5.75$ (Additional file 1) in

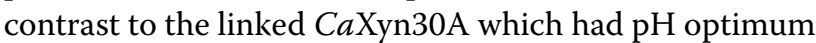
of 4.0 [9]. Temperature optimum was determined at $\mathrm{pH}$ 5.75 and found to be $55^{\circ} \mathrm{C}$ for a $10 \mathrm{~min}$ reaction. The specific activity of $\mathrm{CaXyn} 30 \mathrm{~B}$ measured on BX was approximately $14 \mathrm{U} / \mathrm{mg} \mathrm{CaXyn30B}$ (data not shown).

\section{Discussion}

CaXyn30B is $62 \%$ identical to the genetically adjacent previously described endoxylanase, CaXyn30A. Such high degree of homology would suggest conserved functional specificity but the homology is asymmetrically placed. Specifically, the C-terminal Ricin-like CBM13 domain is $93 \%$ identical while that of the catalytic domain shows $51 \%$ identity. Moreover, identity in the catalytic domain is strongest in the stabilizing side betastructure that when virtually removed reduces identity of the specificity determining regions of the core TIM-barrel of the catalytic domain to $37 \%$. It is only with consideration of conservation within the $\beta 7-\alpha 7$ and $\beta 8-\alpha 8$ loop regions defining the catalytic cleft including conservation of the RR-motif that one would anticipate the function of CaXyn30B to more closely resemble that of the previously described GA-dependent GH30-8 enzyme from B. subtilis, BsXynC, than that of the recently described CaXyn30A.
Such high homology, and it being observed at the nucleic acid level (not shown), is suggestive of a gene duplication event with subsequent diversion in the specificity determining regions. Similarly the high conservation of the CBM13 module suggests similar substrate association albeit with different catalytic specificities. The relative contribution of these two linked enzymes in xylan depolymerization requires further study.

\section{Limitations}

CaXyn30B was tested on a limited number of substrates and conditions were evaluated and the potential for auxiliary activity in addition to the observed GAdependent endoxylanase cannot be ruled out.

\section{Supplementary information}

Supplementary information accompanies this paper at https://doi. org/10.1186/s13104-020-05091-5.

Additional file 1. Optimum reaction conditions determination for (aXyn30B. A) The dependence of activity on $\mathrm{pH}$ showing three overlapping alternative buffer compositions. B) Optimum reaction temperature determined for a $10 \mathrm{~min}$ reaction period.

\section{Abbreviations}

Ca: Clostridium acetobutylicum; GH: Glycosyl hydrolase; GA: Glucuronic acid; CBM: Carbohydrate binding module; Bs: Bacillus subtilis; WAX: Wheat arabinoxylan; BX: Beechwood xylan; SGX: Sweetgum xylan; Ct: Clostridium thermocellum; Cp: Clostridium papyrosolvens; Ec: Erwinia chrysanthemi; Pb: Paenibacillus: GX3: Aldotetrauronic acid. 


\section{Acknowledgements}

MALDI-TOF was performed at the University of Wisconsin Biotechnology Center.

\section{Authors' contributions}

CC and FJSJ designed the study. CC generated CaXyn30B clone, expressed and purified protein. LL performed temperature and pH optimization. FJS J performed TLC and MALDI-TOF experiments. CC generated original draft of the manuscript. All authors read and approved the final manuscript.

\section{Funding}

This study was internally funded by the USDA Forest Service, Forest Products Lab RWU-4712. As a visiting scientist at the Forest Products Laboratory, LL was supported by grants from the Jiangsu Provincial Government Scholarship for Overseas Studies, from the National Natural Science Foundation of China (No. 30370043), the Science and Technology Project of Guizhou Province in China (No. [2019]2333) and the Priority Academic Program Development of Jiangsu Higher Education Institutions.

\section{Availability of data and materials}

Any supporting data or materials are available from the corresponding author upon request.

\section{Ethics approval and consent to participate}

Not applicable.

\section{Consent for publication}

Not applicable.

\section{Competing interests}

The authors declare that they have no competing interests.

\section{Author details}

${ }^{1}$ Institute for Microbial and Biochemical Technology, Forest Products Laboratory, USDA Forest Service, One Gifford Pinchot Drive, Madison, WI 53726, USA. ${ }^{2}$ College of Chemical Engineering, Nanjing Forestry University, Nanjing 210037, China.

Received: 6 February 2020 Accepted: 16 May 2020

Published online: 10 June 2020

\section{References}

1. Aachary AA, Prapulla SG. Xylooligosaccharides (XOS) as an emerging prebiotic: microbial synthesis, utilization, structural characterization, bioactive properties, and applications. Compr Rev Food Sci Food Saf. 2011;10:2-16.

2. Dhiman S, Mukherjee G. Recent advances and industrial applications of microbial xylanases: a review. In: Gehlot P, Singh J, editors. Fungi and their role in sustainable development: current perspectives. Singapore: Springer; 2018. p. 329-48.

3. Valenzuela SV, Diaz P, Pastor FJ. Modular glucuronoxylan-specific xylanase with a family CBM35 carbohydrate-binding module. Appl Environ Microbiol. 2012;78:3923-31.
4. St John FJ, González JM, Pozharski E. Consolidation of glycosyl hydrolase family 30: a dual domain 4/7 hydrolase family consisting of two structurally distinct groups. FEBS Lett. 2010;584:4435-41.

5. St John FJ, Hurlbert JC, Rice JD, Preston JF, Pozharski E. Ligand bound structures of a glycosyl hydrolase family 30 glucuronoxylan xylanohydrolase. J Mol Biol. 2011;407:92-109.

6. Urbániková L, Vršanská M, Morkeberg Krogh KB, Hoff T, Biely P. Structural basis for substrate recognition by Erwinia chrysanthemi GH30 glucuronoxylanase. FEBS J. 2011;278:2105.

7. Vršanská M, Kolenová K, Puchart V, Biely P. Mode of action of glycoside hydrolase family 5 glucuronoxylan xylanohydrolase from Erwinia chrysanthemi. FEBS J. 2007:274:1666-77.

8. St John FJ, Rice JD, Preston JF. Characterization of XynC from Bacillus subtilis subsp. subtilis strain 168 and analysis of its role in depolymerization of glucuronoxylan. J Bacteriol. 2006;188:8617-26.

9. St John FJ, Dietrich D, Crooks C, Balogun P, de Serrano V, Pozharski E, Smith JK, Bales E, Hurlbert J. A plasmid borne, functionally novel glycoside hydrolase family 30 subfamily 8 endoxylanase from solventogenic Clostridium. Biochem J. 2018;475:1533-51.

10. St John FJ, Preston JF, Pozharski E. Novel structural features of xylanase A1 from Paenibacillus sp. JDR-2. J Struct Biol. 2012;180:303-11.

11. St John FJ, Rice JD, Preston JF. Paenibacillus sp. strain JDR-2 and XynA1: a novel system for methylglucuronoxylan utilization. Appl Environ Microbiol. 2006:72:1496-506.

12. Studier FW. Protein production by auto-induction in high-density shaking cultures. Protein Expr Purif. 2005;41:207-34.

13. Laemmli UK. Cleavage of structural proteins during the assembly of the head of bacteriophage T4. Nature. 1970;227:680-5.

14. McCleary BV, McGeough P. A comparison of polysaccharide substrates and reducing sugar methods for the measurement of endo-1, 4- $\beta$-Xylanase. Appl Biochem Biotechnol. 2015;177:1152-63.

15. Nelson N. A photometric adaptation of the Somogyi method for the determination of glucose. J Biol Chem. 1944;153:375-9.

16. St John FJ, Crooks C, Dietrich D, Hurlbert J. Xylanase $30 \mathrm{~A}$ from Clostridium thermocellum functions as a glucuronoxylan xylanohydrolase. J Mol Catal B Enzym. 2017;133:S445-51.

17. Larson SB, Day J, Barba de la Rosa AP, Keen NT, McPherson A. First crystallographic structure of a xylanase from glycoside hydrolase family 5 : implications for catalysis. Biochemistry. 2003;42:8411-22.

18. Gallardo Ó, Fernández-Fernández M, Valls C, Valenzuela SV, Roncero MB, Vidal T, Díaz P, Pastor FJ. Characterization of a family GH5 xylanase with activity on neutral oligosaccharides and evaluation as a pulp bleaching aid. Appl Environ Microbiol. 2010;76:6290-4.

19. St John FJ, Dietrich D, Crooks C, Pozharski E, Gonzalez JM, Bales E, Smith K, Hurlbert JC. A novel member of glycoside hydrolase family 30 subfamily 8 with altered substrate specificity. Acta Crystallogr D Biol Crystallogr. 2014;70:2950-8.

\section{Publisher's Note}

Springer Nature remains neutral with regard to jurisdictional claims in published maps and institutional affiliations.

Ready to submit your research? Choose BMC and benefit from

- fast, convenient online submission

- thorough peer review by experienced researchers in your field

- rapid publication on acceptance

- support for research data, including large and complex data types

- gold Open Access which fosters wider collaboration and increased citations

- maximum visibility for your research: over $100 \mathrm{M}$ website views per year

At BMC, research is always in progress.

Learn more biomedcentral.com/submissions 